BULLETIN Bulletin hispanique

HISPANIQUE Université Michel de Montaigne Bordeaux

114-1 | 2012

Varia

\title{
Hacerse y volverse como nexos pseudo-copulativos
}

dos maneras de concebir el cambio en español

Nicole Delbecque y Lise Van Gorp

\section{(2) OpenEdition}

Journals

Edición electrónica

URL: http://journals.openedition.org/bulletinhispanique/1866

DOI: 10.4000/bulletinhispanique.1866

ISSN: 1775-3821

Editor

Presses universitaires de Bordeaux

\section{Edición impresa}

Fecha de publicación: 1 junio 2012

Paginación: 277-306

ISBN: 978-2-86781-812-7

ISSN: 0007-4640

Referencia electrónica

Nicole Delbecque y Lise Van Gorp, «Hacerse y volverse como nexos pseudo-copulativos », Bulletin hispanique [En línea], 114-1 | 2012, Publicado el 01 junio 2015, consultado el 01 mayo 2019. URL http://journals.openedition.org/bulletinhispanique/1866; DOI : 10.4000/bulletinhispanique.1866 


\title{
Hacerse y volverse como nexos pseudo-copulativos: dos maneras de concebir el cambio en español
}

\author{
Nicole Delbecque \& Lise VAn GorP \\ Katholieke Universiteit Leuven
}

Cette contribution aborde les différences conceptuelles entre les pseudo-copules hacerse et volverse, partant des notions de "réalisation» et de "régression" qui caractérisent leurs emplois lexicaux.

Esta contribución aborda las diferencias conceptuales entre las pseudo-cópulas hacerse $y$ volverse, partiendo de las nociones de "realización» y de "regresión» que caracterizan sus empleos léxicos.

This contribution tackles the conceptual differences between the pseudo-copulas hacerse and volverse, starting off from the notions of "realization" and "regression» that characterize their lexical uses.

Mots-clés: pseudo-copule, changement, sémantique cognitive, signification schématique, perspective, subjectivation.

\section{I. - INTRODUCCIÓN}

El uso de verbos pseudo-copulativos aspectuales que expresan cambio o devenir (hacerse, volverse, ponerse, quedarse, etc.) prevalece sobre el de otros recursos para expresar la noción de cambio en español ${ }^{1}$. Su selección siempre ha constituido un problema para los no hispanohablantes. La dificultad proviene en parte de la diversidad de verbos de los que dispone el espańol como

1. Este estudio forma parte del proyecto de investigación FWO G.0308.10 titulado Why does Spanish have a dozen pseudocopulas to express change-of-state? Towards a cognitive-functional account (dir. Nicole Delbecque, co-dir. Bert Cornillie, doctoranda Lise Van Gorp), subvencionado por el FWO (Fondo de Investigación Científica, Comunidad Flamenca, Bélgica). 
contrapartida de los verbos devenir del francés, diventare del italiano, werden del alemán, worden del neerlandés o to become del inglés ${ }^{2}$. En parte también está en juego el carácter lexicalizado del pronombre reflexivo, desprovisto de papel argumental, en combinación con la gramaticalización de la construcción pronominal para expresar un evento de cambio mediante una predicación calificada de "pseudo-copulativa».

La denominación verbos «pseudo-copulativos» (Alcina \& Blecua, 1975: 898) sugiere que las construcciones en que aparecen se encuentran a medio camino entre las construcciones copulativas y las construcciones no copulativas (Porroche Ballesteros, 1990: 31). Al tiempo que estos verbos comparten características con los verbos copulativos ser y estar, también presentan características propias, por lo cual conviene mantener la distinción entre ellos. Al igual que con los verbos copulativos, el complemento predicativo no es omisible al ser el núcleo semántico de la predicación. Lo que distingue formalmente los pseudo-copulativos de los copulativos es la imposibilidad de pronominalizar el complemento predicativo mediante el clítico lo (Juan es/está loco - Lo eslestá vs. Juan se volvió loco - *Se lo volvió) (véase Morimoto y Pavón Lucero, 2007: 15). Además, por vago e inespecífico que parezca su significado, consideramos que su gramaticalización no implica que adolezcan de significado léxico. Su carga semántica es mayor que la de los verbos copulativos ${ }^{3}$ : expresan, además de un significado atributivo, contenidos como la permanencia (Sigue enfermo), la apariencia (Parece enfermo) o el cambio (Se puso enfermo).

Las publicaciones existentes sobre la noción de cambio en español son más bien estudios globales, preliminares y exploratorios (Crespo, 1949; Coste \& Redondo, 1965; Fente, 1970, Lorenzo, 1970; Eberenz, 1985; Pountain, 1984; Alba de Diego \& Lunell, 1988; Porroche Ballesteros, 1988; Eddington 1999). Es pues un campo que queda por desbrozar. En la presente contribución partimos del MA paper de Lise Van Gorp (2008) para estudiar desde la perspectiva de la semántica cognitiva la relación pseudo-copulativa de cambio expresada por hacerse y volverse. Forman parte de una docena de verbos pseudo-copulativos aspectuales eventivos susceptibles de expresar un cambio (Morimoto y Pavón Lucero 2007: 23), a saber, acabar, caer, hacerse, ponerse, quedar(se), resultar, salir, terminar, venir, volverse, así como devenir y tornarse, de uso menos común.

Tanto hacerse como volverse aportan un significado aspectual a la atribución y perfilan un evento de cambio en que la entidad sujeto pasa a estar en la situación denotada por el complemento predicativo. Primero reseñamos los análisis existentes (apartado dos). A continuación presentamos una hipótesis

2. Los resultados del estudio de Hanegreefs (2000) sobre el verbo neerlandés worden y su traducción española confirman que son las construcciones pseudo-copulativas con verbos de cambio los que se utilizan con mayor frecuencia para expresar la noción de cambio. Sobre un conjunto de 172 ocurrencias, Hanegreefs registra 71 construcciones (el 41,28\%) con estos verbos denominados «de cambio». Otros recursos son perífrasis (llegar a ser, pasar a ser, venir a ser) y verbos derivados de adjetivos (abaratarse, emborracharse, enfermar, abaratarse, etc.).

3. Adviértase que los verbos copulativos tampoco están totalmente vacíos de significado (cf. Delbecque 2000: 248). 
alternativa que aborda la cuestión del significado del verbo y de la construcción desde un enfoque semántico conceptual para captar las imágenes esquemáticas asociadas a los dos verbos a partir de la metaforización de su significado básico: «realización» con hacerse y «regresión» con volverse (apartado tres). A la luz de una serie de ejemplos representativos mostramos que la caracterización en términos gestálticos - «capacitación en continuidad» y «descapacitación en discontinuidad", respectivamente - tiene un alcance mayor que el análisis tradicional en rasgos binarios (apartado cuatro). Luego nos detenemos en la noción de acomodación conceptual, ilustrándola mediante la alternancia entre los dos verbos con unos determinados tipos de sujetos y predicados (apartado cinco). Por último, volvemos sobre la importancia de la posición y el papel del conceptualizador para entender cómo la noción de cambio se presta a un juego de perspectivas, entrelazando una visión objetiva con un punto de vista implícita o explícitamente subjetivo (apartado seis).

\section{II. - ESTUdios PREVIOS: HACERSE VS. VOLVERSE}

Son tres los criterios invocados en la bibliografía mencionada arriba a la hora de distinguir entre los verbos pseudo-copulativos de cambio hacerse y volverse:

a) [+voluntariedad] / [-voluntariedad]. Mientras que hacerse subraya la participación activa e intencionada, volverse sugiere una participación pasiva, no intencionada.

b) [+gradualidad] / [-gradualidad]. Hacerse expresa la idea de un cambio gradual (de superación) (poco a poco, cada vez más), volverse evoca un cambio rápido, brusco o brutal (de repente, de pronto).

c) $[+$ positivo $] /[ \pm$ positivo $]$. Mientras que hacerse suele encontrarse en contextos positivos (progreso, promoción o desarrollo), volverse también se usa en contextos de regresión o democión, es decir, en contextos negativos.

Aunque en muchos contextos, como en (1) y (2), parece comprobarse la pertinencia de estas oposiciones, existen cantidad de casos donde su alcance resulta mucho menos claro. ¿Cómo explicar, por ejemplo, que en (3) el autor haya preferido hacerse para un cambio difícilmente calificable de [+voluntario] o [+positivo]? Además, tampoco resulta más perfilada la dimensión de [gradualidad] en hacerse viejo (3) que en volverse viejo (4) ${ }^{4}$. Y si bien en (4) la valoración del proceso es claramente de signo negativo, la modificación adverbial ni a tiros sugiere que la entidad sujeto (César Romero) opone cierta resistencia a fuerzas contrarias; participa pues en una relación dinámica con el

4. Si bien la vejez es una noción escalar relativa y compleja, que además de la edad comprende nociones como vitalidad, fuerza dinámica y habilidades, evoca una realidad más bien fuera de control o sólo parcialmente controlable. En el ejemplo (3) el aviso que señala la percepción de un umbral significativo da paso a la inferencia de que se es demasiado viejo para jugar bien. 
papel del «agonista» que ejerce una contrafuerza ante entidades «antagonistas» (Talmy 2000a: 413-415).

(1) Imaginación calenturienta: según avanza la historia el narrador gradúa las pausas, enfatiza las expresiones que más le gustan, las saborea como un trago de vino o una tapa de morcilla. En torno suyo el grupo se hace más compacto, la espuma se queda tibia y se deshace en alguna jarra de cerveza, olvidada sobre la barra, como los restos de las raciones que ya nadie va a terminar, y que el camarero no retira. (A. Muñoz Molina, Sefarad. Una novela de novelas, Madrid 2001)

(2) «El público en general debería recordar los tres elementos analizados en la CPSS. Por lo tanto, si el habla de un miembro de la familia se vuelve de repente incomprensible, debería llamarse inmediatamente al teléfono de urgencias. De manera similar, si una parte del cuerpo se entumece o si una parte del rostro se cae, deberían pedir ayuda médica inmediatamente», afirma Hurwitz. (El País, 25/02/2003)

El boxeo, que tiene la virtud de enseñarte a controlar la violencia y dota de una disciplina excepcional, soporta entre otros el defecto de su peligrosidad. Cuando un futbolista se hace viejo, el aviso lo recibe de su entrenador, pero el boxeador lo recibe de los puños del contrario. (La Vanguardia, 22/11/1994)

Cruces salió personalmente a recibirme. Debía de ser uno de los atributos del ayudante del secretario del cónsul. Era un tipazo de metro noventa, gallardo a pesar de su buena sesentena y propietario de una barba canosa de lo más aristocrática. Me recordó bastante a César Romero, que no se vuelve viejo ni a tiros. (E. José, Buster Keaton está aquí, Madrid 1991)

Al perfilarse la dimensión de gradualidad o brusquedad, no es raro que vaya en el sentido opuesto al previsto. Lo atestiguan las modificaciones de golpe en asociación con hacerse en (5) y día a día con volverse en (6). Además, cabe la pregunta de saber desde qué punto de vista se evalúa la gradualidad: en (5), ¿prevalece la perspectiva del participante discursivo Zach Dusteen, la del narrador o es difusa y se extiende a los lectores? En (6), la evolución ¿se sitúa sólo, objetivamente, en la centralización o se sugiere que también evoluciona la percepción subjetiva que tiene el yo narrador ${ }^{5}$ ? La misma pregunta puede plantearse para los ejemplos anteriores. En (1), por ejemplo, el locativo en torno suyo sugiere que se puede interpretar la compactación del grupo no sólo como un hecho perceptible por cualquiera sino antes que nada como una representación mental del narrador. Y en (2), si bien la incomprensibilidad del habla aparece como algo objetivamente comprobable, la especificación de repente también contribuye a limitar en un primer momento el alcance al entorno inmediato.

[...], este buen comienzo se le había ocurrido a Zach Dusteen pero después no supo seguir, las cosas se hacen dificiles de golpe y los caminos se tuercen en el suspiro más inesperado, el capitán del carguero Möre og Romsdal tenía los ojos de color azul celeste y la barba de oro, se llamaba Laars Korvald y mandó tirar a mi padre por la borda antes de que se muriese del todo, la viruela es muy contagiosa y la obligación hay que cumplirla siempre, [....] (C.J. Cela y Trulock, Cristo versus Arizona, Barcelona 1993)

5. Sobre la relación entre perspectiva objetiva y subjetiva, véase Verhagen (2007). 
La mentalidad española había empezado a cambiar cuando la guerra mundial se dio por acabada. España buscaba en aquella paz un nuevo drenaje y la conformidad anterior se resquebrajaba. Existía la posibilidad de una expansión extranjera, nuestro desarrollo económico se minificaba y el peligro de la crisis imponía un cambio de estructuras. Fue entonces cuando le propuse a don Alberto instalar una sucursal en Madrid: «Es absolutamente necesario mantener contacto con la capital. La centralización se vuelve día a día más exigente." Don Alberto dudaba; todavía se aferraba a la idea caduca de una Banca netamente catalana. (M. Salisachs, La gangrena, Barcelona 1976)

Los criterios aducidos pertenecen a niveles de análisis diferentes y son de aplicabilidad limitada. La característica (a) [ \pm voluntariedad] remite a una propiedad agentiva de la entidad afectada por el cambio 6 . Deja fuera de consideración los sujetos no humanos. La característica (c) [ ${ }^{2}$ positivo] supone un sistema de creencias en base al cual un cambio se considera benéfico o maléfico para la entidad afectada. Se trata pues en primer lugar de evaluar el efecto de la propiedad expresada por el complemento predicativo sobre la entidad sujeto. Si bien la pseudo-cópula puede contribuir a orientar el juicio, no basta acudir a hacerse para obtener una lectura positiva de viejo (3) o dificil (5), por ejemplo. Dicho de otro modo, no es a nivel del verbo donde es operativa la modalidad axiológica.

$\mathrm{Al}$ ser eminentemente aspectual el uso pseudo-copulativo, el factor (b) [ \pm gradual], en cambio, sí parece poder formar parte de la tipificación del semantismo del verbo, a condición de concebirlo en términos de (im)posibilidad de escaneo de fases o segmentos en el proceso de cambio. Si bien el concepto de segmentabilidad tiende a corresponder icónicamente a una realización distendida en el tiempo (paso a paso, poco a poco, día a día, lentamente, cada vez más), conviene distinguir entre la gradualidad interna del cambio - o sea, su segmentabilidad - y la proyección del efecto del cambio sobre el transcurso del tiempo. La rapidez a la que se alude por expresiones como de golpe o de repente puede remitir a la velocidad con que se da y percibe el resultado del cambio: la formulación en (5) implica una visión compacta del cambio mismo, o sea, que se tiene una visión global compacta del evento; pero esto no excluye la segmentabilidad del proceso. Al revés, el resultado de un cambio no tiene por qué concebirse como necesariamente estabilizado en el tiempo, sino que puede seguir evolucionando; de ahí que una cuantificación-en-el-tiempo (e.g. día a día más exigente [6]) pueda calificar la intensificación de un estado alcanzado como resultado de un cambio, sin que sea automáticamente segmentable la trayectoria que lleva del estado anterior al nuevo estado (no exigente vs. exigente en [6]). O sea, que en vez de operar una modificación interna de la estructura eventiva, frases adverbiales como día a día o de golpe bien pueden aportar una modificación externa. Si por gradualidad se puede entender la cuantificación-

6. El concepto de agentividad es un concepto complejo y escalar: incluye nociones como fuente, punto de partida, causa, acción, conciencia, intención, control, fuerza, efectividad, y otras parecidas. Abarca, pues, un conjunto de dimensiones de las que el tradicional concepto de agente, entendido como el ser animado realizador de la acción o productor del proceso, no puede dar cuenta sino muy parcialmente. 
en-el-tiempo del grado en que se da la propiedad o el estado expresado por el complemento predicativo, este tipo de modificación adverbial deja de ser fiable como criterio aspectual distintivo porque se hace extensivo a todo predicado susceptible de expresar un estado de $\operatorname{cosas}^{7}$. Así se entiende también que se combina tanto con hacerse como con volverse. En vez de gradualidad, veremos que la noción de (dis)continuidad bien puede resultar más apropiada para distinguir los perfiles relacionales de hacerse y volverse.

\section{III. - Hipótesis: GESTALTS DIFERENTES}

Como se acaba de ver, los criterios propuestos ( $\mathrm{a}$, b y c arriba) para diferenciar entre el uso de los verbos hacerse y volverse sólo tienen un alcance relativo. No son aplicables sino a parte de las ocurrencias y cuando son aplicables no se cumplen en un cien por cien. Esto indica, a nuestro parecer, que no permiten captar la esencia del significado de los dos verbos. Lo cual no quita que puedan apuntar a inferencias típicas o efectos de prototipicidad que se remontan al significado esquemático del verbo.

Para llegar a comprender de forma más satisfactoria lo que determina el uso de hacerse y volverse, conviene adoptar una aproximación semasiólogica centrada en los significados que los verbos expresan fuera de la construcción pseudo-copulativa. Si la noción de gradualidad como segmentabilidad en fases puede retenerse para la caracterización aspectual interna del verbo, se puede suponer que no se trata de una propiedad arbitraria sino que deriva del significado esquemático del verbo. Como ya señalamos en la introducción, la (relativa) gramaticalización del uso pseudo-copulativo no equivale a una total desemanticización. Argüiremos que pervive una parte esencial de la base semántica de los lexemas verbales («lexical persistence» cf. Hopper 1991) y que conviene abordar el significado en términos de estructuras de conocimiento subyacentes. Esto implica que más allá de rasgos semánticos aislados, hay que ir en busca de la Gestalt global que está en juego. El marco semántico conceptual adoptado se diferencia de la semántica referencial por no hacer depender la selección de hacerse o de volverse de la realidad sino de la conceptualización que proyectamos sobre ella, o sea, de la manera de percibir la «realidad».

Según nuestra hipótesis, se asocia a cada verbo una conceptualización esquemática propia, en congruencia con el significado básico que el lexema verbal tiene fuera de la construcción pseudo-copulativa. Partiendo de la metáfora conceptual de que "cambio es movimiento en el tiempo", postulamos que cada verbo convoca una representación distinta de las nociones de kinesis y evolución, sobre la que se proyecta la relación sujeto-complemento predicativo en el esquema pseudo-copulativo. Esto implica que la motivación para optar por un verbo u otro debe buscarse en la proyección de modalidades de movimiento

7. Por ejemplo, Estaba / Estuvo / Se sentía / Se sintió cada vez más enfermo. 
en el espacio (distancia, ritmo, velocidad, etc.), así como de la dinámica de fuerzas, sobre experiencias situadas en el tiempo.

Los famosos versos de Antonio Machado (Proverbios y Cantares, XXIX, 1914) se articulan sobre la tensión antonímica entre hacer y volver proyectada en el espacio:

\author{
$\mathrm{Al}$ andar se hace camino, \\ y al volver la vista atrás \\ se ve la senda que nunca \\ se ha de volver a pisar. \\ Antonio Machado, Proverbios y Cantares, XXIX, 1914
}

Hacer, como hiperónimo de los verbos de acción, es descomponible en los conceptos primitivos "dar a algo su primer ser» (cf. la primera entrada en el DrAe). Según el contexto, podrá alternar con verbos como crear, producir, formar o realizar. Al evocar «acción con resultado", funciona como el prototipo de la noción de causatividad. El isomorfismo entre la realización del cambio y la progresión en el tiempo facilita la emergencia de la imagen de progreso en el uso pseudo-copulativo. En la gramaticalización que lleva de hacer a hacerse entra sin duda una parte de subjetivación. Ésta puede entenderse sea siguiendo el planteamiento langackeriano que postula un sutil proceso de atenuación y desemantización (Langacker 1999b) o asumiendo una aproximación más pragmática que envuelve la presencia creciente del hablante y del oyente en el evento (Traugott, 1988, 1995a, 1995b). De ahí que la factualidad expresada mediante hacerse pueda llegar a interpretarse en términos de cumplimiento de expectativas, y recibir una valoración sea positiva sea negativa.

Volver, por su parte, perfila un cambio de orientación ${ }^{8}$. Este significado engloba esencialmente tres tipos de conceptualización: movimiento giratorio, inversión de la dirección, o cambio no especificado de la orientación. En su uso transitivo volver señala un movimiento que no implica desplazamiento y la orientación del movimiento inducido no es específica sino que depende sobre todo del tipo de entidad y de su estado o posición inicial (puede ser tanto girar como dar la vuelta). Al usarse intransitivamente, volver expresa un evento de cambio de lugar. Se caracteriza como un verbo de trayectoria que implica un cambio de orientación (cf. Cuartero Otal, 2009: 264). Su direccionalidad va determinada por el punto de llegada, con la particularidad de que éste se concibe como el punto de origen de un desplazamiento anterior?. El movimiento expresado mediante volver se concibe pues como un movimiento "hacia atrás», o sea, que va a contracorriente de la representación icónica de un movimiento

8. En la Gramática Cognitiva cada evento comprende un elemento que se perfila (la figura o «trayector») y cierta información contextual (la base). La base incluye el oyente, el hablante y las circunstancias sociales, físicas y emocionales que constituyen el evento en su conjunto. En cada predicación se selecciona una figura para darle prominencia respecto a la base.

9. A diferencia de lo que ocurre con la pareja deíctica ir y su reverso venir, la direccionalidad no depende de la perspectiva del conceptualizador. 
efectuado por una entidad agentiva orientada por defecto hacia delante. A diferencia del verbo regresar, que también significa "ir al sitio de donde se salió», volver no perfila la dimensión agentiva como tal, y el foco de atención no recae necesariamente en el final de recorrido, sino que puede quedar limitado al segmento inicial del cambio de rumbo.

Mientras que la imagen asociada a hacer es una de progresión en la continuidad, la imagen de interrupción y retroceso que vehicula volver se caracteriza más bien por su discontinuidad. Por la discrepancia entre la línea del tiempo y el sentido del cambio, la evolución tiende a ser percibida como contraria a las expectativas y abre fácilmente el paso a una apreciación negativa del cambio, tachable de desvío y deterioro. Estas diferencias de conceptualización y las nociones clave que de ahí se derivan para el uso pseudo-copulativo y para posibles mecanismos inferenciales se recogen en la Tabla 1.

\begin{tabular}{|c|c|c|}
\hline & hacer & volver \\
\hline significado básico & $\begin{array}{c}\text { acción con resultado: } \\
\text { formación, efectuación } \\
\text { > realización }\end{array}$ & $\begin{array}{l}\text { inversión por movimiento } \\
\text { giratorio o regresivo } \\
\text { > regresión }\end{array}$ \\
\hline$\longrightarrow$ PSEUDO-CÓPULA & $\begin{array}{c}\text { CONTINUIDAD } \\
>(\text { AUTO)CAPACITACIÓN }\end{array}$ & $\begin{array}{c}\text { DISCONTINUIDAD } \\
>(\text { AUTO)DESCAPACITACIÓN }\end{array}$ \\
\hline $\begin{array}{l}\text { proyección en el } \\
\text { tiempo }\end{array}$ & $\begin{array}{l}\text { proceso incremental: } \\
\text { con el tiempo se gana } \\
\text { sustancia }\end{array}$ & $\begin{array}{l}\text { proceso reverso: } \\
\text { con el tiempo se pierde } \\
\text { sustancia }\end{array}$ \\
\hline visión evolutiva & $\begin{array}{l}\text { crescendo: avance } \\
\sim \text { ascenso } \quad \text { progresión }\end{array}$ & $\begin{array}{l}\text { decrescendo: marcha atrás } \\
\sim \text { descenso }- \text { regresión }\end{array}$ \\
\hline conceptualización & desarrollo esperado, normal & evolución marcada, alteración \\
\hline valoración simbólica & cumplimiento prototípico & desviación del prototipo \\
\hline alcance más amplio & $\begin{array}{l}\text { ley de vida, progreso, } \\
\text { destino }\end{array}$ & revés, desvirtuación, fatalidad \\
\hline
\end{tabular}

Tabla 1. - Conceptualización del cambio expresado por hacerse y volverse

Si se hace abstracción de la posible presencia de factores que determinen el cambio, las nociones de capacitación, respectivamente descapacitación, pueden calificarse en términos reflexivos, es decir, como auto-capacitación y autodescapacitación. En la Tabla 1 el prefijo auto- se pone entre paréntesis porque, como veremos, hay casos en que el proceso viene activado desde fuera de la entidad sujeto. La fuerza instigadora puede estar presente en el contexto. La fuente también puede situarse entera en la mente del conceptualizador; en tal 
caso, el proceso afecta la imagen que éste tiene de la entidad sujeto sin implicar que corresponda necesariamente con un cambio ocurrido u ocurriendo en el ámbito de la entidad sujeto misma.

Sea como sea, sin embargo, la progresión en el tiempo, tal como la perfila hacerse, se concibe en términos incrementales, como progresión y acierto esperados por defecto a la luz de algún modelo cognitivo subyacente. Con volverse, en cambio, se destaca la dimensión regresiva, concebida como una desviación respecto de lo prototípico y orientada hacia la degradación y la desintegración. A escala más amplia, las dos visiones se integran en marcos de creencia ${ }^{10}$ antagónicos: ley de vida asimilada a progreso y destino, por un lado, y revés, contratiempo, desvirtuación por obra de la fatalidad, por otro.

\section{IV. - IMAGEN ESQUEMÁTICA Y CONTEXTUALIZACIÓN}

La validación de la hipótesis requiere que se proceda al examen de una variedad de contextos por verbo para comprobar en qué medida la imagen asociada al evento de cambio presenta las propiedades reunidas en la Tabla 1. Este enfoque es complementario al adoptado por Bybee \& Eddington (2006), quienes centran todo su interés en el complemento predicativo sin ocuparse de especificar el significado del verbo ${ }^{11}$. Se basan en la frecuencia y ejemplaridad de algunos complementos predicativos adjetivales o preposicionales con hacerse, ponerse, quedar(se) y volverse para argüir que la expresión del cambio presenta un alto grado de convencionalización en español, y que la extensión a adjetivos nuevos, menos frecuentes, procede por analogía semántica.

Por ahora nos parece primordial privilegiar la dimensión relacional. En una fase ulterior, con un muestrario más amplio, proyectamos comparar los resultados con las agrupaciones de complementos predicativos establecidas por Bybee y Eddington (2006). La evidencia empírica en que nos apoyamos aquí proviene de un corpus de prosa peninsular novelística y periodística constituido a partir de CREA. A continuación nos enfocamos en los indicios contextuales que permiten arrojar luz sobre la conceptualización asociada con el verbo ${ }^{12}$.

\section{IV.1 Hacerse : imagen de progresividad}

Por proyección metafórica, el cambio perfilado mediante la pseudocópula hacerse, concebido como movimiento en el tiempo, representa fundamentalmente el paso «de nada a algo», o por lo menos el avance a un nivel

10. Cf. los «folk models» popularizados desde Lakoff (1987).

11. Lit.: "we leave further specification of the verbs' meanings for future study» (Bybee $\&$ Eddington 2006: 334).

12. A partir del CREA (Corpus de Referencia del Español Actual) se ha constituido un corpus de 300 contextos, 150 por verbo, que constan de formas del presente de indicativo de la tercera persona singular y plural. La selección queda limitada al español peninsular. 
superior, haciendo eco a las nociones de creación y producción que caracterizan el significado de hacer. Pervive la noción de irreversibilidad propia de un proceso de creación así como la fuerza dinámica asociada con la noción de producción. Al mismo tiempo, sin embargo, el uso pseudo-copulativo supone un proceso de desagentivización (cf. Langacker 1999b).

La imagen de progresividad asociada con el cambio expresado mediante hacerse parece guardar tres dimensiones constitutivas, a saber, progresión, movimiento ascendente y fases alineadas. La Figura 1 esquematiza su configuración: la línea horizontal flechada que indica la progresión según el vector temporal, refleja la unidireccionalidad del cambio en la base; la línea quebrada ascendente que apunta en la misma dirección ocupa la posición central y va en negrita para indicar que, por defecto, la trayectoria se recorre según fases ordenadas, lo cual equivale a decir que el proceso es segmentable. Hacerse aparece así como la pseudo-cópula de la progresividad: la progresión en el tiempo corresponde a un movimiento ascendente internamente ordenado.

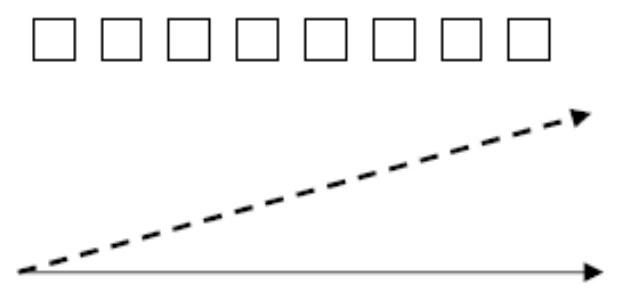

Fig. 1. - Significado esquemático de hacerse como pseudo-cópula: movimiento ascendente de progresión ordenada en fases.

A la luz de esta aproximación gestáltica, los rasgos propuestos en la bibliografía para el verbo hacerse, a saber, [+voluntario], [+gradual], [+positivo] (véanse los puntos a, b y c del apartado 2), se dejan reanalizar como efectos de prototipicidad. Corresponden a expectativas que pueden encontrarse reforzadas o debilitadas según el contexto. Al nivel de las inferencias, que se realizan en base a los conocimientos enciclopédicos, suponemos que un cambio en términos de progresión ascendente tenderá por defecto a ser deseado, intencional y valorado positivamente, a concebirse en términos de gradualidad y a interpretarse como formando parte del curso natural de las cosas, de la razón de ser de una entidad y, más en particular, el destino o la vida de una persona. Si bien la ley de vida se comprueba por excelencia en la representación de las edades del hombre (7), la misma linealidad puede proyectarse sobre el desarrollo interno de una trayectoria socioprofesional, una vida dentro de la vida en cierto modo, como es la carrera de un deportista (3).

[...] luego seguiremos jugando, espera y verás, he tenido una idea genial, ella estaba ya delante de él, era delgada y frágil, qué curioso, pensé, en los países anglosajones los niños se hacen grandes antes que las nińas, la levantó sin esfuerzo, no pesaba nada, la 
tomó de las corvas y separó los brazos, la mantuvo en vilo, qué malo, pero qué malo eres, ya entiendo, la chica era muy lenta, yo lo adiviné antes que ella, ya entiendo, quieres que me haga pis, aquí, ahora, el corderito intentó escapar [...] (A. Grandes, Las edades de Lulú, Barcelona 1995)

Conviene insistir, sin embargo, en que tales aproximaciones no dejan de ser el reflejo de modelos cognitivos idealizados (cf. Lakoff y Johnson 1980, Lakoff $1987)^{13}$. O sea, que las expectativas en cuanto a voluntariedad, gradualidad y positividad no tienen por qué cumplirse siempre. Si bien en un ejemplo como (8), el cambio se percibe como un movimiento unidireccional ascendente, marcado por una serie de fases alineadas (con continuas referencias al pasado), resulta que la valoración va en sentido negativo (difícil, crispado) y que la entidad afectada por el cambio (la conversación con Blasfemo) ya presentaba cierto grado de dificultad. Lo cual no concuerda con la idea de que hacerse se usa para señalar una "cualidad, estado o situación de los que antes un ser carecía» (Alba de Diego y Lunell 1988: 344). Por estos dos motivos se consideraría un caso menos prototípico desde la óptica tradicional. En términos gestálticos, sin embargo, la evolución de una interacción ya conflictiva hacia mayor enfrentamiento e incomunicación resulta natural y esperable. En la muestra analizada, difícil es, además, el complemento predicativo más frecuente (7 casos de los 150).

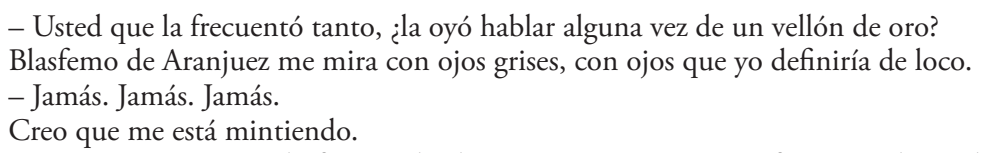

La conversación con Blasfemo, a borbotones, con continuas referencias al pasado, se hace difícil, crispada. (R. del Pozo, Noche de tabúres, Barcelona 1995)

Se acude típicamente a hacerse para cambios considerados como pertenecientes al curso natural de las cosas. En (8) se entiende que la conversación que avanza a borbotones y con continuas referencias al pasado no puede sino avanzar por vericuetos cada vez más difíciles. En cambio, queda sin especificar si la constatación emana (sólo) del narrador-comentarista extradiegético o si (también) refleja el punto de vista intradiegético del yo narrador, el personaje que conversa con Blasfemo ${ }^{14}$.

La proyección del espacio al tiempo según una lógica inherente al curso de las cosas se ilustra a la perfección en el fluir del río evocado en (9): su cauce atraviesa sucesivos dominios territoriales. Si bien se trata de un transcurso que aparece como natural y de una categorización (andaluz) que radica en una base de conocimientos enciclopédicos, activada en el contexto (... desemboca por

13. Un modelo cognitivo idealizado (MCI) es un concepto (o conglomerado de conceptos relacionados) que define nuestro conocimiento de una categoría. Más precisamente, MCIs son gestalts complejos que incorporan cuatro tipos de principios estructuradores: estructura proposicional, imágenes esquemáticas, proyecciones metafóricas y metonímicas. Acudimos a MCIs para entender el mundo.

14. Compárese con el mismo atributo en (5) y con exigente en (6). 
Ayamonte...), conste que la perspectiva evolutiva introducida por la pseudocópula siempre es el reflejo de la perspectiva elegida por el conceptualizador.

-Y tiene como afluentes principales -señaló- el Guadalimar y el Jándula por la derecha y el Genil por la izquierda. Otro río importante, que al final se hace andaluz, es el Guadiana, que nace en las lagunas de Ruidera y desemboca por Ayamonte, provincia de Huelva, haciendo frontera con Portugal.

- Los dos ríos hacen la Andalucía baja. (J. Asenjo Sedano, Eran los días largos, Barcelona 1982)

$\mathrm{Al}$ igual que las fronteras regionales, comarcales, etc. sirven de pauta para medir la progresión en el espacio, el ciclo de los días del año, las horas del día, etc. forman el cańamazo para evaluar la progresión en el tiempo. En contextos didácticos como el de (9) la finalidad comunicativa puede considerarse neutra. En otros contextos, en cambio, no suele ser el caso, ni siquiera cuando se enuncian constataciones aparentemente anodinas y se procura objetivarlas, como en (10) por la referencia a la hora (qué hora es) o en (11) por el cálculo correlativo de la duración de los días y de las noches. La orientación argumentativa puede revelarse de varias maneras: la presencia de un marcador discursivo movilizador (mira en [10]), la invocación de un evento inminente que requiere cierta preparación (el contexto subsiguiente en [10]) o el enfoque en un efecto benéfico (compensan... [11]). Significa que la selección de la pseudo-cópula tiene un valor cognitivo-funcional que infunde una determinada aproximación evaluativa subjetiva al discurso.

Mira qué hora es: se hace tarde, nuestro invitado de honor puede llegar en cualquier momento y encontrarnos en la mesa. (E. Mendoza, La verdad sobre el caso Savolta, Barcelona 1994)

[...] y a partir de ahí seguirá un descenso continuado de las temperaturas. Todo esto coincide con que los días se van acortando sensiblemente, mientras que las noches se hacen más largas y compensan el bochorno soportado durante el día. Hoy siguen las presiones relativamente bajas sobre España, con la baja térmica en su centro. (El País, 01/08/1986)

Otro tanto puede decirse de la conceptualización de fuerzas que animan elementos de la naturaleza ambiental (12) u orgánica (13). La dimensión subjetiva destaca más cuando el complemento predicativo denota una cualidad sensorialmente perceptible (grandes [7], intensa [12], apremiante [13]), o de índole psico-reactiva (molesto [14]) o evaluativa (difícil [8]). El radio de acción del efecto causado puede variar: la escena puede envolver al propio enunciador como experimentante (12) u observador (13), concebirse de forma vaga, implicando un grupo inespecífico de participantes (en [14] el viento alcanza a quienquiera esté, no sólo a los dos niños) o, al contrario, centrarse en los participantes en el evento (los niños en [7] y los dialogantes de [8]).

La construcción pseudo-copulativa difiere conceptualmente de posibles variantes construccionales con predicadoverbal.Adiferenciadelas construcciones transitivas directas (apremiar, molestar, dificultar), la construcción pseudocopulativa no perfila una relación de causación directa, con efecto asegurado 
en entidades-pacientes, sino que destaca la dinámica interna desarrollada por la entidad sujeto: por ejemplo, el viento arrecia de modo que se hace muy molesto (14). Al igual que en las predicaciones ergativas (envejecer [3], crecer [7], atardecer [10], alargarse [11], intensificarse [12]), el proceso se concibe como auto-contenido; la diferencia es que la predicación pseudo-copulativa no se limita a presentar una entidad como el locus donde ocurre el cambio, haciendo caso omiso de una posible instigación externa, sino que le atribuye una propia fuerza dinámica.

(12) Debía de ser muy tarde, esa hora previa a las primeras luces del alba en la que la oscuridad se hace más intensa. Irene dormía a mi lado, pero yo tenía el estómago revuelto y no podía conciliar el sueño. (P. Zarraluki, La historia del silencio, Barcelona, 1995)

Se reclina luego en la butaca y se mantiene en silencio. No hay placidez, sin embargo, en su expresión. Alguna tensión interior mantiene curvadas las comisuras de sus labios y el silbido de sus pulmones, de vez en cuando, se hace más apremiante, como el pitido de una locomotora que se acerca a un paso a nivel sin guarda. (J. Tomeo, Amado monstruo, Barcelona, 1995)

(14) Dos niños corretean entre las mesas de la terraza, el viento arrecia y se hace muy molesto. (J. Marsé, El embrujo de Shangai, Barcelona 1996)

La imagen de un aumento en efectividad concebido prioritariamente en términos de autocapacitación es el denominador común. Con complemento predicativo nominal, se señala que la (auto-)energización opera un cambio de categoría: trátese de la humanización de materia inerte (15) o de la materialización de representaciones mentales $(16,17)$, se mantiene la direccionalidad y el aspecto realizativo inherente al semantismo de hacer. La noción de «factura» se transparenta en la conceptualización de estas trasmutaciones ${ }^{15}$.

Despierta el que estaba dormido, el barro se hace persona. (F. Umbral, Mortal y rosa, Barcelona 1995)

Era como un sueño que se hace realidad. (J. Leguina, Tu nombre envenena mis sueños, Barcelona 1992)

Otra tesis de Robespierre que se hace realidad. (J.M. Fajardo, La epopeya de los locos, Barcelona 1990)

Asimismo hacerse perfila la dinámica que empuja a sectores de actividad. Un caso como (18) presenta un interés particular. Como el complemento predicativo es un adjetivo relacional ${ }^{16}$, no es graduable ( ${ }^{*}$ muy supranacionales). Significa que la modificación de grado (cada vez más) no incide en el complemento predicativo sino en la predicación. Por la constelación compuesta y plural de la entidad sujeto, sin embargo, pueden darse dos lecturas. En la más descriptiva, la predicación afecta a un tipo de entidad concebido como estable, a saber,

15. La paráfrasis con convertirse subraya la afinidad entre la construcción con complemento predicativo nominal y la mediopasiva.

16. Para este tipo de adjetivos también se utilizan otras denominaciones, e.g. «clasificadores» o «categorizadores». 
las economías nacionales, y hacerse remite a la extensión del radio de acción de las economías nacionales, proceso calificado de progresivo (cada vez más). Las indicaciones locativas (Unión Europea, Mercosur) y cuantitativas del contexto que apuntan a la extensión del entorno institucional (de 12 a 15 paises, [...] se ha ampliado) parecen corroborar esta interpretación. En paralelo, sin embargo, también es posible una lectura más subjetiva. En ésta, la modificación de grado envuelve a la entidad sujeto, cuya subcategorización (nacionales) deja de concebirse como estable. Se obtiene entonces una lectura recategorizadora: «las economías dejan de ser economías nacionales para convertirse en economías supranacionales»'. La modificación de grado se interpreta entonces en un sentido secuencial («las economías de un país tras otro», o sea, «de cada vez más países») y las indicaciones locativas y cuantitativas se acomodan a esta lectura distributiva.

(18) La Unión Europea (UE) ha pasado de 12 a 15 países miembros y en Iberoamérica ha nacido Mercosur. Las economías nacionales se hacen así cada vez más supranacionales, al tiempo que la Organización Mundial de Comercio (OMC) y los acuerdos de la Ronda Uruguay, que ahora entran en vigor, han abierto un proceso que en el próximo decenio deberá estimular los intercambios comerciales y el crecimiento económico... La Unión Europea se ha ampliado, a partir del 1 de enero, del Á rtico a la frontera rusa y hasta Europa Central, con la entrada de Suecia, Finlandia y Austria. (La Vanguardia, $02 / 01 / 1995)$

Por último, la configuración conceptual compleja y multifacética de ciertas entidades sujeto hace que la conceptualización del avance que se les atribuye parece teñirse de un mayor grado de subjetividad que en los casos anteriores. Tratándose de sujetos cuya conceptualización oscila entre segundo orden - con proyección primaria en el tiempo - y tercer orden - sin proyección espaciotemporal - , resulta posible enfocar tanto una serie de representaciones sucesivas, con estructuración heterogénea en el tiempo, como adoptar un punto de vista globalizador y homogeneizador ${ }^{17}$. Así, según prevalezca en (19)(21) una óptica u otra, la interpretación de la relación establecida mediante la pseudo-cópula podrá considerarse más descriptiva, o sea, objetivada, o más subjetiva, dependiente de un punto de vista particular. En bodas (19) hay una vertiente procesual realzada por los verbos (me casé, acaban celebrándose) y la progresión en el tiempo segmentada por las fases evocadas (se pactan, se acuerdan, se anuncian). En esta visión evolutiva objetivada, son las bodas en su desenlace las que aparecen como lógicas e irremediables; lo corrobora el carácter plenamente procesual de la secuencia subsiguiente: ya por eso suele acabar celebrándose.

17. Mientras personas, animales y objetos físicos discretos son entidades «de primer orden», Lyons (1991: 170) considera que son «de segundo orden» entidades que se refieren a eventos, situaciones o estados de cosas que ocurren o existen en el mundo físico, y que son «de tercer orden» las que carecen de locación espaciotemporal; estos objetos «intensionales» (e.g., proposiciones, conceptos individuales) no pueden ser designados deícticamente, contrariamente a las entidades de los primeros dos órdenes. 
Sin embargo, además de calificaciones aspectuales que remiten a la estructuración en el tiempo de entidades eventivas, estos adjetivos también pueden remitir a la opinión personal del enunciador (el yo del relato); entonces destaca más bien la vertiente abstracta (tercer orden), y se considera la entidad sujeto como objeto de tipificación. Así, en una de esas relaciones de amistad inesperadas [...] (20) se entrecruzan los dos niveles de interpretación. Por un lado hay la lógica interna atribuida a una determinada experiencia relacional situada en el tiempo y caracterizada por darse proporcionalmente menos a medida que se avanza en edad (a partir de la cuarentena). Por otro lado, al valor aspectual del enrarecimiento puede mezclarse un valor modal epistémico arraigado en la subjetividad del narrador, a quien la mayor improbabilidad de ocurrencia sirve de criterio de categorización para un particular tipo de amistad.
Me casé con ella cuando ya no la quería si es que la quise, uno hace esas cosas por sentido de la responsabilidad, del deber, por debilidad momentánea, algunas bodas se pactan, se acuerdan, se anuncian, y se hacen lógicas e irremediables, ya por eso suelen acabar celebrándose. (J. Marías, Corazón tan blanco, Barcelona 1994)

\begin{abstract}
Ya es hora de que lo presente porque sin él, la verdad, Eguren, con su probada torpeza para asuntos de la vida ordinaria y su poética rebeldía, probablemente hubiese dado en loco, aunque esto sea, como casi todo, mucho decir: Txomin Ciordia. Una de esas relaciones de amistad inesperadas que a partir de la cuarentena se hacen verdaderamente raras. Un hombre tranquilo, según muchos. (M. Sánchez-Ostiz, Un infierno en el jardin, Barcelona 1995)
\end{abstract}

En cuanto a (21), si bien el sujeto la cuestión representa una abstracción, se desprende del contexto que no le corresponde una vaga categorización concebida como homogénea sino que recoge una pluralidad de reacciones mentales - o sea, eventos cognitivos - que se producen respecto de un entorno a su vez múltiple y variado (artes del espacio). En la medida que las sucesivas evocaciones (creación... misterio... acto creador... lo logrado... súbita y oscura iluminación de nuestra sensibilidad...) se proyectan metafóricamente como estadios sucesivos en el camino seguido por el pensamiento, y por ende en términos de progresión factual, hacerse sigue perfilando un proceso incremental, objetivado en el discurso. La parte (inter)subjetiva proviene del anclaje de la caracterización graduada (más compleja) en una pluralidad de conceptualizadores que incluye al comentarista-enunciador (estaríamos... nuestra sensibilidad... conocimiento... intuitivamente... las profundidades de nuestro ser...). Si bien no parece quedar aquí sino una reminiscencia muy diluida del valor semántico primario de hacer, cabe notar sin embargo que lo que viene a continuación remite a un modelo de conceptualización que tiene su parte de «creación» y «transformación»: los ojos, depositarios del misterio, añaden interpretación (la contemplación, la forma cabal de valorarlo). Significa que la propia perspectiva judicativa aparece como evolutiva. Lo cual sugiere que la desemantización de hacerse es menos marcada que en la contrapartida francesa se faire, cuya subjetivación puede presentar un cierto carácter evidencial (Lauwers/Duée, 2011). 


\begin{abstract}
Toda creación auténtica se halla en posesión del misterio. Quiero decir con ello que la esencia del acto creador es irreductible y que lo logrado mediante el mismo no tiene, en el fondo, explicación alguna, no puede ser calibrado con fórmulas racionales. Si no fuera así, el arte dejaría de serlo y estaríamos ante un orden de experiencias distintas, quizá muy interesantes, pero sin esa súbita y oscura iluminación de nuestra sensibilidad. El arte es también una forma de conocimiento; y sin embargo, no lo es intelectualmente sino intuitivamente, recalado en las profundidades de nuestro ser. Cuando se trata de un arte visual, de las llamadas artes del espacio, la cuestión se hace más compleja aún, porque, en definitiva, son los ojos los depositarios del misterio y es la contemplación la forma cabal de valorarlo. (J. Perucho, Dietario apócrifo de Octavio de Romeu, Barcelona, 1985)
\end{abstract}

\title{
IV.2 Volverse: imagen de regresión
}

$\mathrm{Al}$ igual que con hacerse, los rasgos propuestos en la bibliografía para volverse (cf. apartado 2) tampoco tienen la vigencia de condiciones necesarias: si bien la ausencia de voluntariedad y gradualidad, así como la tendencia a una valoración más bien negativa, se ven corroboradas en muchos contextos, no faltan ejemplos contrarios. Estos rasgos se dejan reanalizar como efectos de prototipicidad que varían mucho en función del contexto. Y como se acaba de ver para hacerse, puede entrar en juego una dimensión evidencial cuando el complemento predicativo remite a la perceptibilidad de la entidad sujeto y la actividad cognitiva de los perceptores.

El tipo de caso ilustrado en (22) es excepcional con volverse. Este contexto reúne las condiciones para situar el cambio no primeramente en el fenómeno como tal, sino en el acceso visual - y por ende cognitivo - que se tiene a él.

Dudo que lo que pedalea cansinamente unos metros por delante nuestro sea Jabato, dudo incluso que sea un hombre en el sentido íntegro de la palabra. También él, como la montaña, se ha transformado en otra cosa. La lasitud de su pedalada se vuelve perceptible. Vemos tomas aéreas, filmadas desde el helicóptero, y principalmente desde la moto de Antenne-2 que va circulando tras él con gran dificultad. (J. García Sánchez, El Alpe d'Huez, Barcelona 1995)

En las líneas anteriores el narrador ocupa una posición privilegiada respecto de la escena: en tanto seguidor en una etapa del Tour de France asiste al desgaste que el esfuerzo en la montaña produce en el ciclista Jabato (dudo... lo que pedalea cansinamente). En el sujeto de la construcción pseudo-copulativa se estabiliza la imagen de falta de vigor (la lasitud). El punto de mira pasa de la figura del corredor en su globalidad a la parte más relevante, el movimiento giratorio con que empuja la bicicleta (su pedalada). Como se necesita la suficiente cercanía para captar con nitidez la manera de pedalear, y el complemento predicativo de potencialidad perceptible sugiere discontinuidad con la visión panorámica anterior, la pseudo-cópula volverse se interpreta en términos de reajuste focal. Lo corrobora la referencia subsiguiente al realizador de televisión que hace alternar la filmación a distancia con los primeros planos ofrecidos por el cámara motorista. Se entiende que con la trasmisión de imágenes en close-up, los telespectadores se encuentran, de un momento para otro, capacitados para darse cuenta a su vez del estado de fatiga del corredor ciclista. 
En suma, el uso de volverse en este contexto viene motivado por la discontinuidad en la sucesión de imágenes. Con hacerse no se haría totalmente caso omiso de una posible evolución (continua) en la imagen que emana del atleta. En la medida que éste sea susceptible de dar señales cada vez más visibles de su agotamiento, la evolución arraigada en el objeto de percepción, o sea, la perspectiva "objetiva» interna podría coexistir con la perspectiva externa. Tal combinación, sin embargo, encajaría mal en el contexto de (22).

Por lo general, el complemento predicativo no es de índole perceptual. El dominio cognitivo al que pertenece suele determinar la orientación argumentativa. La valoración negativa proviene en primer lugar de la combinación de volverse con adjetivos calificativos que denotan un defecto (enclenques [23], sordos [24], desconfiado [25]). Y si bien éstos, al aplicarse a un sujeto humano, suelen considerarse no intencionales (24), el descontrol no es necesariamente total (25).

Además, la supuesta brusquedad no parece tener que ver tanto con la rapidez del proceso de cambio cuanto con la fuerza del contraste que la predicación pseudo-copulativa introduce con elementos del contexto. En (23), por ejemplo, la imagen de una expansión urbana vigorosa y saludable se ve suplantada con la imagen inversa: debilitación y carencia de fuerzas. En (24), se contraponen en una misma perspectiva enunciativa la pretensión (irónica) del afinamiento del oído propio frente al ensordecimiento general de los coetáneos. En (25), la modalidad repentina sugerida por la modificación temporal de pronto refuerza el carácter sorprendente de la conversión de un cándido en su contrario, un ser desconfiado.

El tío Rodolfo aseguraba que las ciudades crecían tanto, que cuando menos se esperaba ya no tenían afueras (...), ni descampados, ni zonas montańosas, con árboles capaces de prestar vigor y salud. "Por eso, cuando las ciudades crecen demasiado, se vuelven enclenques.» Era su teoría. Entonces la mayoría de la gente de aquella época emitía vulgaridades como catedrales, pero todo lo que aquel hombre decía, me parecía importante. (M. Salisachs, La gangrena, Barcelona 1976)

Por el pasillo le llega un llanto infantil, como si lo hubieran suscitado sus pensamientos. No suena irritado ni plañidero, sino rítmico, tranquilo: afirma una existencia. «Me gusta», piensa el viejo, así lloraría yo si alguna vez llorase... ¿Esos pasos, la Andrea?... No, canturrea otra voz; es Renato... ¡Qué cosa!, todos los viejos se vuelven sordos, pero a mí se me afina el oído; valgo ahora más para escucha que cuando me tocaba de avanzadilla en la partida... (J. L. Sampedro, La sonrisa etrusca, Madrid 1995)

Eguren no estaba hecho para vivir en buena armonía con nadie en un mundo que le resultaba cada vez más ininteligible. Eso al menos es lo que él se decía. A un cándido que se vuelve de pronto desconfiado se le ponen las cosas sencillamente pardas. Una vida, la suya, que estaba visto se regía por otras normas, otras reglas, otra y bien distinta ley de la gravedad, ley ingrávida la suya: jinete solitario, explorador del Teneré, Robin Hood, Quijote cuando le llegue la edad de estar algo más que mitad cuerdo mitad descerrajado, marino fantasma, músico callejero, titiritero... No pintaba nada en el mundo de los vivos. (M. Sánchez-Ostiz, Un infierno en el jardín, Barcelona 1995)

Para captar el perfil de la relación pseudo-copulativa expresada por volverse conviene recordar que el semantismo de volver supone una inversión de orientación o el abandono del rumbo seguido anteriormente. La relación con 
una anterioridad permite ver mejor lo que tienen en común las construcciones con volverse: se perfila una media vuelta ya no en el espacio sino en el tiempo y a nivel simbólico. Un desarrollo colectivo que deja de ser progreso (23), una capacidad orgánica que se desgasta (24), una virtud que se pierde (25), y hasta el agotamiento en un atleta de alto nivel (22), no son sino algunas de las múltiples ocurrencias que van en contra de modelos cognitivos idealizados en que estriban nuestras expectativas de progreso y continuidad.

Volver marca una ruptura. Usar volverse como pseudo-cópula equivale a perfilar un cambio que interrumpe la continuidad en el tiempo. A la luz de las distinciones pertinentes para definir los significados básicos de volver (cf. apartado 3), pueden retenerse tres imágenes esquemáticas de una reorientación centrada en la posición de la entidad afectada por el cambio. En un movimiento sin desplazamiento (tipo [i]), la entidad se ve sometida a una pérdida de orientación, que se puede representar prototípicamente como un movimiento giratorio, y que perfila el comienzo de una nueva trayectoria, la cual aparece como versátil y caótica. Con desplazamiento y trayectoria de dirección inherente se dan dos posibilidades. Sea se da a ver una imagen de inversión de polaridad, una marcha atrás con retorno al punto de arranque, en contrapartida de un movimiento inicial (tipo [ii]). La media vuelta tiende prototípicamente a perfilar el final de la trayectoria. Sea, por extensión, queda la idea de un cambio de rumbo, entendido como pérdida de continuidad -y posiblemente pérdida de orientación-, con sólo el punto de partida como punto de anclaje (tipo [iii]); se entiende típicamente en términos de descenso, o sea, de degradación.

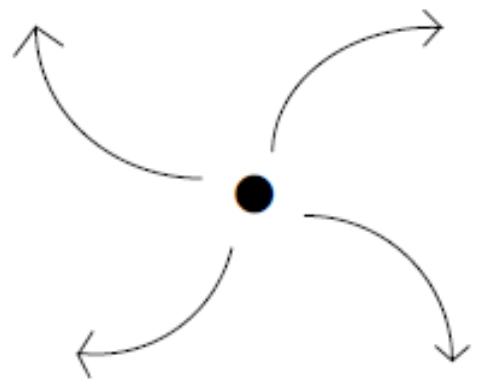

Fig. 2a. - Significado esquemático de volverse como pseudo-cópula: versatilidad.

Con volverse como pseudo-cópula, el cambio se entiende pues como el exponente de una multitud de posibles cambios. Para captar este potencial semántico acudimos a una triple representación. La figura 2 a evoca la versatilidad que el verbo volverse proyecta sobre la realidad. Y según se adopte una visión circular o lineal, el cambio se asimilará a un retroceso, una vuelta al punto inicial (Figura 2b) o a una regresión, un descenso de nivel (Figura 2c). 
Pervive, pues, una parte de la base semántica del verbo volverse, a saber, el cambio de dirección.

Según se trate de la naturaleza en general (26), un elemento individual no animado (una estrella [27]) o animado (las gaviotas [28]), la versatilidad introducida por volverse adoptará formas diferentes: pérdida del compás de las temporadas (26), salida de la órbita (27), incapacitación para mantener el rumbo (28). En todo caso, con volverse la pérdida (involuntaria) de fuerza y de control se asemejan a desorientación.

El domingo 20 de abril de 1997, este periódico titulaba así un reportaje: Marzo mayea y la naturaleza se vuelve loca. Antes de aquel marzo tan caluroso y seco, España conoció uno de los inviernos con los peores temporales del siglo; después, mayo marceó, el verano se enfrió y el otońo se llenaba de mangas cortas y toldos en las terrazas mientras en Alicante navegaban en barcas por las calles. Ahora se avecinan días de frío invernal. Los meteorólogos corroboran que estamos ante uno de los años más atípicos de la historia. (El País, 14/10/1997)

Si una estrella de órbita conocida deambulara por las inmediaciones de dos agujeros negros, ¿sería posible predecir por cuál de ellos sería engullida? No. Unas veces la estrella caería en uno, otras en el otro y tal vez hasta se librara de ese destino fatal siguiendo de largo; no se puede saber qué pasaría porque la trayectoria de un astro en esas condiciones se vuelve caótica. (El País, 29/10/1997)

- Es el levante -le explicó Andrés, señalando el cielo con la mano derecha para no abandonar a Alfonso, a quien seguía intentando acompañar con la izquierda-. Acaba de entrar, y ha entrado fuerte. Las gaviotas se vuelven locas, ¿¿lo ves?, no saben para dónde ir. Al principio dan vueltas como tontas en el aire, van hacia un lado, hacia el otro, pierden altura de repente... Es como si se les olvidara volar. (A. Grandes, Los aires dificiles, Barcelona 2002)

(29) ¡Oro! -fue la firme respuesta de éste cuando su ama y señora le preguntó su opinión sobre la mejor forma de atraer al esquivo capitán hasta su hamaca-. Los españoles se vuelven locos por el oro. Ofréceselo y le tendrás a tus pies como un esclavo. (A. VázquezFigueroa, Caribes (Cienfuegos 2), Barcelona 1990)

La alteración que afecta a seres animados se atribuye fácilmente a alguna fuerza exterior: si la desorientación de animales suele tener causas naturales (e.g. el viento del levante [28]), la alienación y desazón humana parece explicarse más bien por tentaciones (e.g. el afán de lucro [29]) o inhibiciones (e.g. la inseguridad ante lo diferente y desconocido [30]).

El calificativo que más fácilmente se asocia a volverse es el adjetivo loco, cuyo significado primario corresponde precisamente a la pérdida de la razón, el juicio, la sensatez. Representa la décima parte de los ejemplos en el corpus $(15 / 150)$. En la aplicación metafórica a la naturaleza (26) y a animales (28) se manifiesta la presencia de un modelo antropocéntrico del mundo. Como se ve en (27)-(30) no suelen faltar indicios contextuales que corroboren la versatilidad expresada por la pseudo-cópula. En (27), por ejemplo, se evoca con lujo de especificaciones lo caótico de la trayectoria de una estrella. Tratándose de seres humanos, la inhabilitación suele asociarse a modales indeseados (e.g. timido y distraido [30]). 
Odia a las mujeres y a las niñas porque se siente ridículo ante ellas. Pierde la espontaneidad y se vuelve tímido y distraido. Es tierno porque aún no ha desarrollado la malicia y la supuesta listeza de los adolescentes tardíos. Los trece-catorce años marcan el límite atroz, cuando todavía es posible de él todo lo mejor. (C. Rico Godoy, Cómo ser una mujer y no morir en el intento, Madrid 1995)

En la medida que en (30) la inducción de una pérdida de rumbo por un factor exterior (las personas del otro sexo) resulta en una inversión de polaridad (pierde la espontaneidad), se trata de un caso de transición hacia el tipo (ii) (Figura 2b).

Cuando el retroceso equivale a la pérdida de la calidad más sustancial, culmina en la desintegración total de la entidad sujeto. Tal extremidad se reconoce por el carácter paradójico o antonímico de la relación entre sujeto y complemento predicativo: sal / sosa (31), amor / desamor (32), amigos buenos / malos (33) forman auténticos oxímoros, o sea, que la relación aparece casi como una contradictio in terminis. De ahí que contraposiciones como las que se dan en (31) y (32) incluso adquieran valor aforístico.

$$
\text { ¿Para qué sirve la sal si se vuelve sosa? (El Diario Vasco, 07/02/2001) }
$$

Los amigos son buenos hasta que se vuelven malos. (A. Pérez-Reverte, La Reina del sur, Madrid 2002)
Pero han transcurrido solamente seis horas y sin embargo cuánto tiempo, cómo las penas hacen multiplicarse los minutos, de qué modo les hacen alargarse como si pasasen años, lustros, inmensidades de ira. Y de qué modo el amor se vuelve desamor y todo cambia rotundamente. (J.M. Merino, Novela de Andrés Choz, Madrid 1987)

Por lo general, sin embargo, aparecen factores explicativos. En (33), la inversión de positividad en negatividad (amor/desamor) plasma la culminación de un desquicio reflejado en el desajuste entre tiempo real y tiempo vivido (seis horas/cuánto tiempo; minutos/años, lustros).

Si bien la inversión de la polaridad, representada en la Figura $2 \mathrm{~b}$, suele interpretarse en términos de desvirtuación, ésta puede presentar varias modalidades en función del tipo de entidad sujeto y de la contrafuerza. En (34), la dilución (vapor) del líquido (lluvia) se produce bajo el efecto inmediato del calor (cañón ardiente). En (35), la inflexión es epistémica -se refiere a la comprensión de textos-y se apoya en una metáfora táctil: la equiparación con manteca (sustancia blanda por excelencia) realza cómo una lectura experta (leer entre líneas) fuerza el acceso a las sentencias más firmes. 


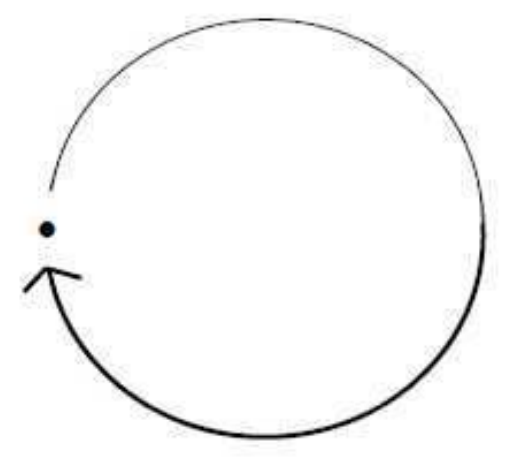

Fig. 2b. - Significado esquemático de volverse como pseudo-cópula: inversión de polaridad.

(34) Tira una ráfaga corta a la derecha y otra a la izquierda, hijos de la, murmura, corre cinco o seis metros más y se agacha de nuevo. La lluvia se vuelve vapor al tocar el cañón ardiente del arma. (A. Pérez-Reverte, La Reina del Sur, Madrid 2002)

(35) Cuando se acostumbra a leer entre líneas ningún texto puede prevalecer sobre otro y las sentencias más firmes se vuelven manteca. (J. Benet Goitia, Saúl ante Samuel, Madrid 1994)

En (36) convergen la inversión de polaridad (Figura 2b) y la desnivelación (Figura 2c). La reducción de amplitud que media entre españolista y regionalista corresponde tanto a un movimiento anti-orientado, hacia dentro, como a una bajada de categoría. Nótese que los criterios tradicionales no se cumplen ni en (35) ni en (36): no se supone brusquedad ${ }^{18}$, hay cierta intencionalidad (se acostumbra a leer entre líneas [35], para buscar... para influir [36]), y el resultado se valora positivamente (lo que asumo [36]).
La nación tiene que ver con un hecho lingüístico, cultural, pero también con la revolución industrial, el comercio con América, los movimientos migratorios, la aparición de una burguesía claramente españolista que defiende un mercado nacional español y que, cuando se frustran sus expectativas de entrar en el gobierno de España, se vuelve regionalista para buscar una alternativa para influir en la política española. Eso es lo que asumo cuando digo que soy nacionalista. (La Vanguardia, 16/11/1995)

La tercera variante (Figura 2c) es la más esquemática: no queda sino la imagen de una evolución contrarrestada por algún bloqueo o fuerza mayor que impide avanzar en la misma línea e implica una pérdida de nivel.

18. Sería diferente con una subordinada temporal introducida por en cuanto o apenas en vez de la conjunción no marcada cuando. 


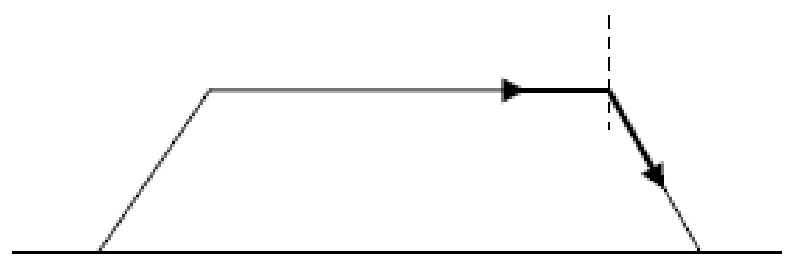

Fig. 2c. - Significado esquemático de volverse como pseudo-cópula: pérdida de nivel.

Otra vez, como se ve en (37)-(40), el cambio no tiene por qué ser brusco ni implicar necesariamente «alteración o conversión en algo distinto, opuesto o contrario» (así reza parte de la definición del Diccionario Clave). Y si bien en (37) se evalúa negativamente una pérdida de calidad (circula con dificultad), no es el caso en (38)-(40). Al contrario, en (38) el cambio sobrevenido parece tan positivo que requiere de una matización (mismos efectos adversos) para frenar entusiasmos inconsiderados. En (39) y (40) el resultado de una evolución gradual (cada vez más sinuosas, van perdiendo el color verde) se vincula con sus beneficiarios (esto atrae a los hebreos cabalistas [39]) o con una apreciación enaltecedora (amarillas... oro, rojizas... cobre).

Las gotas de sudor quitan algunos grados de temperatura al cuerpo cuando se evaporan. Pero el sudor es agua que se saca de la sangre. Así, el líquido rojo pierde volumen, se vuelve espeso y circula con dificultad, aunque el corazón le pida la misma cantidad para bombear los órganos vitales. (La Vanguardia, 06/07/1994)

Actualmente las personas infectadas con el virus de inmunodeficiencia humana tienen que tomar hasta una docena de píldoras al día a horas determinadas y la FDA cree que de esta forma el tratamiento se vuelve más fácil, aunque ha advertido que la nueva combinación tiene los mismos efectos adversos que cada uno de los fármacos por separado. (El Pais, 30/09/1997)

Conquistas y reconquistas influyen en el grosor y complejidad de sus murallas. Encorsetada entre baluartes y fortificaciones concéntricas, sus calles se vuelven cada vez más sinuosas; esto atrae a los hebreos cabalistas de Gerona, que fundan sucursales de su secta allí y cavan pasadizos que conducen a sanedrines secretos y a piscinas probáticas descubiertas en el siglo xx al hacer el metro. (E. Mendoza, La ciudad de los prodigios, Barcelona 1993)

En otoño, las arboledas van perdiendo el color verde, unas hojas se vuelven amarillas, hasta parecer de oro, y otras rojizas como el cobre.(J. M. Merino, La orilla oscura, Madrid 1995)

Independientemente de la intencionalidad, gradualidad y valoración, volverse marca pues una discontinuidad cuyo efecto puede ir de la degradación y deterioro (Figura 2c) a la desestabilización y desorientación (Figura 2a), pasando por la desvirtuación e implosión (Figura 2b). Como se ha visto en (30) y (36), no son ramos separados sino fuertemente intrincado s: al punto 
nevrálgico realzado en la primera representación (Figura 2a) se añade la noción de la trayectoria inversa (Figura 2b) o desviada (Figura 2c) respecto del (supuesto) camino previo.

\section{Mecanismos de acomodación}

Se da por supuesta la compatibilidad entre la propiedad o categoría expresada por el complemento predicativo y el tipo de entidad denotado por el sujeto. Es bien sabido que la congruencia entre ambos va regida fundamentalmente por la distinción entre lo que es humano, humanizado o humanizable, y lo que no lo es ${ }^{19}$.

Sin embargo, más allá de las restricciones léxicas, también conviene prestar la debida atención a los mecanismos de acomodación que intervienen en la conceptualización de la relación entre el sujeto y el complemento predicativo. Sea cual sea la categoría léxica y semántica de uno y otro, la relación entre ambos se adapta al perfil conceptual impuesto por la pseudo-cópula.

Casos de alternancia entre hacerse y volverse como los reseñados a continuación se aclaran a la luz de la diferente conceptualización del cambio. Existen, en efecto, restricciones que no son definibles a nivel del solo sujeto o complemento predicativo, sino que se explican por la conceptualización de la relación predicativa.

Nos detenemos primero en el ámbito corpóreo ([41]-(45]) antes de ilustrar brevemente la diferencia con imágenes mentales ([46]- [47]) y con colores ([48]- [49]).

De ciertas zonas activas del cuerpo humano, como la sonrisa, la mirada o la voz, puede emanar cierta expresividad. En (41) se sugiere que Clara modula su voz, calificada de grave y vibrante; con hacerse se señala control y dirección; lo corroboran indicaciones contextuales como el adverbio volitivo (deliberadamente) y la construcción final (para llegar...). En (42), en cambio, la instrumentalización de la voz no aparece como intencionada; el aumento de melosidad (más melosa), si bien delata intenciones manipuladoras, parece escapar al control del personaje. Al determinar el perfil relacional, el verbo arroja una luz diferente sobre la funcionalidad de la entidad sujeto: con hacerse la voz se ve como instrumento de persuasión al servicio del emisor (41), con volverse como seña reveladora de su estado de ánimo (42).

\footnotetext{
Y Clara está sentada muy erguida sobre las piernas dobladas, en la cama contigua a la mía, con un suéter desteñido y un pantaloncito corto, también desteńido y azul, que habrá encontrado perdidos en algún rincón del armario de los niños. Tiene la boca trémula y risueña, y su voz, grave y vibrante, se hace más fina y queda, se viste deliberadamente de terciopelo, para llegar a mi encuentro convertida en caricia, y
}

19. Sirvan de ilustración los ejemplos de Alba de Diego \& Lunell (1988: 346): Luis se hizo médico - *El cielo se hizo médico / El tiempo se puso malo - ${ }^{*}$ El tiempo se puso enfermo / La pared se volvió negra - ${ }^{*}$ La pared se volvió alegre. 
cuando, ante un gesto mío -he alargado la mano sin ni tan siquiera abrir los ojos-, ella se precipita hacia mí, se precipita como un torrente a arremansarse sobre mi hombro [...] (E. Tusquets, El mismo mar de todos los veranos, Barcelona 1990)

- Mary Ann... por Dios -no quiero ni discutir-. Estoy agotado.

- Por supuesto, perdona. Cuelgo y vuelves a dormirte. Sólo quería que lo supieras -su voz se vuelve más melosa al agregar-: Pásate por aquí y lo hablaremos con más calma. - ¿Y él?

- No estará, descuida. (J. Sierra i Fabra, El regreso de Johnny Pickup, Madrid 1995)

De forma análoga la motoricidad de algunas partes del cuerpo puede enfocarse de dos maneras: hacerse las perfila con actividad propia, volverse les quita la iniciativa. Así, en (43), el contexto evoca la evolución de las manos, desde objeto de (des)cuidado a su autonomización: la habilitación es tal que actúa por sí misma e imprime su orientación a la persona (vamos detrás de nuestra mano, que nos arrastra).

Las manos, en la infancia, fueron como garras que la madre, cada cierto tiempo, tenía que lavar, pulir, recortar, limar, para devolverles su calidad de manos, su humanidad. Hemos tenido épocas de cuidarnos mucho las manos y épocas de olvidarlas casi por completo. La mano se hace ladrona por sí misma, o se afemina, o se cierra con violencia. Realmente, vamos detrás de nuestra mano, que nos arrastra y quiere cumplir su destino. (F. Umbral, Mortal y rosa, Barcelona 1995)

En (44) y (45) el cambio realza estados inhabituales, degradados e inhabilitados de la cara. Mientras en (44) volverse presenta la pérdida de identidad (anónima) de la cara de un muerto como una inversión de polaridad (cf. Figura 2b), en (45) la discontinuidad perfilada se limita a la alteración bajo el efecto de las lágrimas (cf. Figura 2c).

(44) Estoy tendido viendo en la oscuridad los hilos de luz que siguen brillando en mis ojos aunque la linterna se ha apagado y espero como una res a que vengan a matarme, un guerrillero ruso que no ha visto nunca mi cara, que se olvidará de ella en cuanto me haya degollado, porque no se puede recordar la cara de un muerto, se vuelve anónima en cuanto la vida ha desaparecido de ella, y por eso nos hacen tan poca impresión los muertos que hay siempre cerca de nosotros, pudriéndose en las alambradas, hinchándose en el barro, los muertos apilados sobre los que nos sentamos a veces para descansar mientras tomamos el rancho. (A. Muñoz Molina, Sefarad. Una novela de novelas, Madrid 2001)

Voy al baño a por kleenex. Me miro en el espejo. La verdad es que no estoy tan mal llorando. Las caras de las mujeres cuando lloran de verdad se vuelven intensas y contienen una belleza aterradora como las esculturas de Gaudí. (C. Rico Godoy, Cómo ser una mujer y no morir en el intento, Madrid 1995)

En cuanto a la memoria como imagen mental, compárese (46) y (47). Hacerse subraya que se respeta la lógica natural de su destino (borrarse con el tiempo). Volverse, en cambio, marca la excepción a la regla bajo una circunstancia particular (al partir). 
Lo mismo que el recuerdo de algunas vivencias personales que nos habían parecido imborrables, la memoria de aquello que hemos visto con la imaginación, porque no alcanzamos a vivirlo, también se hace borrosa con el tiempo, también se desgasta. (J. Marsé, Rabos de lagartija, Barcelona 2000)

A veces, en el curso de un viaje, se escuchan y se cuentan historias de viajes. Parece que al partir el recuerdo de viajes anteriores se vuelve más vivo, y también que uno escucha y agradece más las historias que le cuentan, paréntesis de valiosas palabras en el interior del otro paréntesis temporal del viaje. (A. Muñoz Molina, Sefarad. Una novela de novelas, Madrid 2001)

Por último, contrariamente a lo que se ha podido afirmar (véase Porroche Ballesteros 1988: 136), los adjetivos de color no siempre se construyen con volverse. Compárese (40) y (48) con (49). En los últimos dos casos el cambio se refiere a un cielo. Al igual que la transición de verde a amarillo y rojizo en (40), el paso de azul ora a gris ora a blanco (48) se concibe como una desviación del prototipo; volverse hace percibir el cambio como el exponente de una variedad de cambios posibles (cf. Figura 2a); la versatilidad que el verbo proyecta sobre la realidad se comprueba aquí en los indicios contextuales algunos días y otros. En (49), en cambio, el contexto es metalingüístico: un creador ante el papel en blanco duda qué color ponerle al cielo (pintado mental antes que materialmente) (estuvo por añadirle gris o azul... como un Pantócrator, estaba el creador del cielo azul o gris) y se centra en la tonalidad que toma su conciencia (... la sensación de que...). El verso "El cielo azul se hace gris» refleja la evolución de un horizonte mental («como mi alma entre las hojas»). Al expresarse mediante hacerse, la transición se aborda en términos de progresión sin discontinuidad, no de regresión en discontinuidad como habría sido el caso con volverse.

Pero, a lo mejor, el pájaro que canta metido dentro de la jaula no sabe que aquello de color azul, aquel recuadro azul que mirando para arriba recortaban las paredes del patio, se llama cielo. Un cielo cuadrado, reducido, que algunos días se vuelve gris, otros blanco, y otras veces es alegrado por el paso de una nube de algodón que vuela de prisa. Que pasa y se va. (I. Palou, Carne apaleada, Barcelona 1975)
Estuvo por añadirle gris o azul pero dudó, tachó, corrigió, retenido por un sentimiento de indómita abundancia, una mano en la mejilla y la otra débilmente extensa, como un ex voto, sobre el papel en blanco, mientras alrededor las cosas habían ido tomando posiciones, unas piadosas y otras excusadas, hasta componer un retablo pensativo en cuyo centro, como un Pantocrátor, estaba el creador del cielo azul o gris, acechado celosamente por una lámpara. Tuvo de pronto la sensación de que la realidad se adelgazaba en un hilo diamantino de luz y que pasaba limpiamente por el ojo certero de una aguja. "El cielo azul se hace gris / como mi alma entre las hojas», fueron sus primeros versos. (L. Landero, Juegos de la edad tardía, Barcelona 1993)

La flexibilidad que se acaba de ilustrar no significa que no pueda haber tendencias en el uso. Con un corpus más amplio será posible comprobar la fuerza de ciertas tendencias, por ejemplo, la relación preferente con hacerse de entidades que suponen control y direccionalidad, tal como la mirada o el gesto, y la mayor correlación entre volverse y entidades que carecen de control y progresividad. 


\section{VI - ReFLEXIONES FINALES}

A lo largo del análisis se ha podido constatar que los criterios aducidos en la bibliografía, a saber, [ \pm voluntariedad], [ \pm gradualidad] y [ \pm positividad], no permiten captar de manera satisfactoria lo que motiva la selección de hacerse o volverse. Si la alternancia se decidiera en función de una combinación de rasgos, carecería de significado a nivel relacional. Además, al cumplirse los tres criterios, la selección aparecería como redundante y, al no cumplirse o al cumplirse sólo parcialmente, la alternancia revestiría un carácter aparentemente arbitrario y seguiría inexplicada.

En este estudio, hemos adoptado una perspectiva diferente, considerando que cada pseudo-cópula aporta un significado esquemático propio a la relación entre entidad sujeto y complemento predicativo. Según nuestra hipótesis, el perfil impuesto por hacerse y volverse no puede definirse por las habituales distinciones aspectuales sino que corresponde a una conceptualización diferente del cambio.

Partiendo del significado que hacer y volver tienen fuera de la construcción pseudo-copulativa, hemos postulado que en virtud de una cierta persistencia léxica, hacerse mantiene una visión realizativa mientras que con volverse el cambio se concibe como alteración. Así, volverse sugiere que de un felino no se espera que sea sedentario (50) ni de niños que sean formales (51).

\footnotetext{
Por supuesto que surgen dudas: ¿`Y si después de la operación engorda? ¿Y si [el felino] se vuelve sedentario? ¿Y si su carácter se altera? Sólo el veterinario tiene las respuestas a estas interrogantes. (El Universal, 27/12/2004)
}

\section{La tertulia campestre se adensa considerablemente con estas dos presencias familiares, pero tan singulares. Hasta los niños se vuelven más formales. (F. Umbral, Leyenda del} César visionario, Barcelona 1995)

Con hacerse la (auto)capacitación atribuida a la entidad sujeto suele corresponder a un proceso incremental congruente con la noción de progreso. Con volverse se da la imagen inversa de una (auto)descapacitación, un proceso degresivo congruente con la noción de pérdida de prototipicidad. Según que se elija hacerse o volverse, se da a ver otro tipo de cambio. Dicho de otro modo, la selección es reveladora del marco interpretativo adoptado y las valoraciones a las que puede dar paso son el reflejo de modelos cognitivos idealizados. Al optar por hacerse prevalece una visión prototípica, al preferir volverse se introduce cierta discrepancia respecto de la imagen prototípica de la entidad sujeto.

$\mathrm{Si}$ bien es cierto que siempre es crucial el papel del conceptualizador, a veces pasa claramente a ocupar el primer plano. Para ejemplos como (19), (20), (21) y (22) hemos comentado el fenómeno de la subjetivación, haciendo hincapié en que la identificación de la perspectiva del conceptualizador dista de ser una cuestión simple. La percepción de un cambio puede concebirse de tres maneras: situando el cambio en el objeto percibido (modalidad descriptiva centrada en el percepto), situándolo en el perceptor (modalidad epistémica) o situándolo tanto en el percepto como en el perceptor. Adjetivos epistémicos 
(del tipo evidente, manifiesto, cierto, lógico, difícil, probable) remiten a una toma de conciencia, o sea, una activación mental. Pero incluso en casos con una interpretación epistémica como (52), con sujeto abstracto (la realidad) y complemento predicativo epistémico (patente), no queda excluido que cierta evolución siga siendo imputable a la entidad en cuestión (se vuelve necesidad acuciante).

-Toda moral no es sino la justificación de una necesidad, entendiendo por necesidad el exponente máximo de la realidad, porque la realidad se hace patente al hombre cuando traspone los dominios de la elucubración y se vuelve necesidad acuciante; la necesidad, por tanto, de una conducta unánime ha hecho surgir de la mente humana la idea de moral. (E. Mendoza, La verdad sobre el caso Savolta, Barcelona, (1975) 1994)

En el juego de perspectivas interviene la correlación entre tiempo y espacio: la evolución que se observa en la imagen de una entidad puede ser debida a una modificación de la distancia que media entre esta entidad y el punto desde donde se la mira. De ahí que convenga prestar la debida atención a la mención de la distancia como factor determinante: en (53), la clave de la inversión de polaridad (la figura de un conocido / un extraño) está en la especificación espacial (a esa distancia); en (54), la experiencia sensorial del cambio de ruido ( más sordo) se vincula explícitamente con el desplazamiento efectuado por los conceptualizadores (según vamos cruzando... ). En tal caso se hace abstracción de posibles modificaciones en la fuente del ruido; si bien es dudoso, aunque posible, que paralelamente el mar haga menos ruido, es sobre todo irrelevante porque se relega al trasfondo a partir del momento en que la perspectiva subjetiva lo gana sobre la perspectiva objetiva y pasa a ocupar el primer plano.
y me pregunto cómo habría podido verme alguien que me observara entonces desde una ventana sin que yo lo advirtiese, mientras caminaba por esas mismas calles tan intoxicado de palabras y quimeras como el poeta calé, la figura de un conocido que a esa distancia se vuelve un extraño y apenas ve lo que tiene a su alrededor, la ciudad habitada de fantasmas turbios del deseo y de los libros. (A. Muñoz Molina, Sefarad. Una novela de novelas, Madrid 2001)

\begin{abstract}
De tal modo nuestra fama crece hasta donde ni mi misma hermana llegó a pensar. Así este viaje más que asustarla le hace crecerse, la afirma y asegura. Aun como ciegas, sin ver otra cosa que lo que las cortinas nos permiten, bien se aprecia que el mar que nos envuelve crece y arrecia, se hace más sordo según vamos cruzando la calle principal, según retumban en ella los cascos de las mulas y las voces. (J. Fernández Santos, Extramuros, Barcelona 1994)
\end{abstract}

Sin una aproximación fenomenológica anclada en la subjetividad del conceptualizador resultaría difícil dar cuenta de un ejemplo como (55). La escena entera se ve desde la perspectiva del paseante (uno); la impresión de que los puntos de referencia se esfuman proviene del efecto óptico natural de empequeńecimiento que se produce a medida que el perceptor se aleja del punto de mira: la imagen se va reduciendo en su "pantalla» mental y al cambiar de dimensión, el resultado es que los elementos se hacen irreconocibles. 
(55) Es la monotonía. O tal vez sea el aire o la luz, pero los puntos de referencia se esfuman porque, al cambiar de dimensión, se hacen irreconocibles. Es por eso que puede uno perderse tan fácilmente. (F. Schwartz, La conspiración del Golfo, Barcelona 1983)

(56) ¿Era simplemente una singularidad o un rasgo común entre los que se hacen monjes? (El País, 18/02/2003)

(57) - Por falta de comprensión.

- Sí, yo creo que la homosexualidad se ceba en parte de esa circunstancia.

- Pero Ramón antes se vuelve monje que marica. (L. Beccaria, La luna en Jorge, Barcelona 2001)

Con todo, la intrincación que caracteriza los ejemplos (19)-(22) y (52)-(55) supera la usual. Por lo general, el contexto no presenta mayor complejidad y se perfila un cambio que no supone movilidad otra que la de la entidad sujeto. Independientemente del punto dellegada, hacerse perfila una progresión realizada en la continuidad, volverse una evolución marcada por la discontinuidad. Así, por mucho que a la luz de nuestros conocimientos enciclopédicos una determinada categorización, e.g. monje, se entienda como un cambio voluntario, cuya consecución presenta una graduación institucionalmente codificada, con una finalidad socialmente valorada, volverse le confiere un carácter contingente (57), mientras que hacerse confirma su Gestalt vocacional (56). Como se ha visto que ocurre a menudo, el contexto inmediato presenta elementos congruentes que contribuyen a la coherencia discursiva: en (57), la particularización (Ramón) se enmarca en un giro adversativo (pero) y pseudo-comparativo (antes que maricón); en [56]) el interrogante tiene un alcance genérico (una singularidad o un rasgo común entre los que). En último resorte, sin embargo, es en la dimensión paradigmática donde se encuentra la corroboración estructural del significado del nexo pseudo-copulativo. 


\section{Bibliografía}

Alba de Diego Vidal y Lunell Karl-Axel, «Verbos de cambio que afectan al sujeto en construcciones atributivas», en Peira P., Jauralde P., Sánchez Lobato J. y Urrutia J. (Eds.), Homenaje a Alonso Zamora Vicente. Volumen I: Historia de la Lengua: El español contemporáneo, Madrid, Castilia, 1988, p. 343-359.

Alcina Franch Juan y Blecua José Manuel, Gramática española, Barcelona, Ariel, 1975.

Bybee Joan y Eddington David, "A usage-based approach to Spanish verbs of "becoming" ", Language 82:2, 2006, p. 323-355.

Coste Jean y Redondo Augustin, Syntaxe de l'espagnol moderne, Paris, 1965.

Crespo Luis A., «To become», Hispania 32:2, 1949, p. 210-212.

CREA, Corpus de Referencia del Español Actual, [en línea]. Real Academia Española. Disponibilidad y acceso http://www.rae.es

Cuartero Otal Juan, Cosas que se hacen: esquemas sintáctico-semánticos agentivos del español, Frankfurt a.M., Lang, 2003.

— "¿Cuántas clases de verbos de desplazamiento se distinguen en español?», RILCE Revista de filología hispánica 22:1, 2006, p. 13-36.

— «Clases aspectuales de verbos de desplazamiento en español», Verba: Anuario galego de filoloxia 36, 2009, p. 255-291.

Delbecque Nicole, "Las cópulas ser y estar: categorización frente a deixis», Revista Española de Lingüistica aplicada, 2000, p. 239-279.

- Linguistique cognitive: comprendre comment fonctionne le langage, Brussel, De Boeck, 2006.

DRAE, Diccionario de la lengua española [Vigésima segunda edición en línea]. Real Academia Española. Disponibilidad y acceso http://www.rae.es

Eberenz Rolf, "Aproximación estructural a los verbos de cambio en Iberorromance», Linguistique comparée et typologie des langues romanes 2, 1985, p. 460-475.

Eddington David, "On 'becoming' in Spanish: A corpus analysis of verbs expressing change of state» [Manuscrito en línea]. 1999. Disponible en [http://linguistics.byu.edu/ faculty/eddingtond/become.html].

Fente Rafael, «Sobre los verbos de cambio o devenir», Filología Moderna 38, 1970, p. 157-172.

Hanegreefs Hilde, El verbo neerlandés worden y su traducción española, Leuven: tesina de licenciatura, 2000.

Hopper Paul J., «On Some Principles of Grammaticization», en Traugott Elizabeth Closs y Heine Bernd (Eds.), Approaches to Grammaticalization. Volume I: Focus on theoretical and methodological issues, Amsterdam-Philadelphia, John Benjamins, 1991, p. 17-36.

Lakoff George y Johnson Mark, Metaphors we live by, Chicago, University of Chicago Press, 1980.

Lakoff George, Women, fire, and dangerous things: What Categories reveal about the Minds, Chicago,University of Chicago Press, 1987.

Langacker Ronald W., 1999a. Grammar and Conceptualization. Berlin / New York: Mouton de Gruyter. 1990. Cognitive Linguistics Research 14.

— «Losing Control: Grammaticization, Subjectification, and Transparency», In Blank A. y Koch P. (Eds.), Historical Semantics and Cognition, Berlin / New York, Mouton de Gruyter, 1999b, p. 147-175. 
Lauwers Peter y Duée Claude, «From aspect to evidentiality: the subjectification path of the French semi-copula se faire and its Spanish cognate hacerse», Journal of Pragmatics 43:4, 2011, p.1042-1060.

Lorenzo Emilio, «Sobre los verbos de cambio», Filología Moderna 38, 1970, p. 173197.

Lyons John, Essays in linguistic theory. 1, Natural language and universal grammar. Cambridge, Cambridge University Press, 1991, 290 p.

Maldonado González C. y otros (Eds.), CLAVE Diccionario de uso del español actual, Madrid, Ediciones SM, 2006.

Morimoto Yuko y Pavón Lucero María Victoria, Los verbos pseudo-copulativos del español, Madrid, Arco Libros, 2007.

Porroche Ballesteros Margarita, Ser, estar y verbos de cambio, Madrid, Arco Libros, 1988.

- Aspectos de la atribución en español, Zaragoza, Libros Pórtico, 1990.

Pountain Christopher P., "La noción de "devenir" en español», Boletín de la Asociación Europea de profesores de Español 31, 1984, p. 111-116.

Talmy Leonard, Toward a Cognitive Semantics. 1, Concept structuring systems. Cambridge (Mass), The MIT Press, 2000a.

Traugott Elizabeth Closs, "Pragmatic Strengthening and Grammaticalization», en Axmaker S., Jaisser A. y Singmaster H. (Eds.), Proceedings of the Fourteenth Annual Meeting of the Berkeley Linguistics Society. Berkeley, Berkeley Linguistics Society, 1988, p. 406-416.

- "On the rise of epistemic meanings in English: An example of subjectification in semantic change», Language 65, 1989, p. 31-55.

- "The Role of the Development of Discourse Markers in a Theory of Grammaticalization», Paper presented at ICHL XII, Manchester, 1995a.

— «Subjectification in grammaticalization», En Stein D. y Wright S. (Eds.), Subjectivity and subjectivisation in language, Cambridge, Cambridge University Press, 1995b, p. 31-54.

Van Gorp Lise, Verbos de cambio: hacia una explicación cognitiva. Hacerse y volverse, Leuven: MA paper, 2008.

Verhagen Arie, "Construal and Perspectivization», en Geeraerts Dirk y Cuyckens Hubert (Eds.), The Oxford Handbook of Cognitive Linguistics, Oxford, Oxford University Press, 2007, p. 48-81. 